\title{
Respiratory function and self-reported functional health: EPIC-Norfolk population
} study

\author{
P.K. Myint*, R.N. Luben*, P.G. Surtees*, N.W.J. Wainwright*, A.A. Welch*, \\ S.A. Bingham ${ }^{\#}$, N.J. Wareham ${ }^{\star}$, N.E. Day* and K-T. Khaw*
}

ABSTRACT: Respiratory function is known to be associated with mortality. However, its association with health related quality of life (HRQoL) has not yet been examined.

A population-based cross sectional study was conducted in 16,738 subjects aged 40-79 yrs and resident in Norfolk, to examine the association between forced expiratory volume in one second (FEV1) and HRQoL measured by the 36-item short form questionnaire.

Individuals who were in the highest quintiles of FEV 1 were more likely to report good physical functional health (odds ratio (OR) 1.60; 95\% confidence interval (Cl) 1.28-2.01 and OR 1.71; 95\% Cl 1.40-2.10 for males and females, respectively) controlling for age, height, weight or body mass index, smoking, physical activity, prevalent illness and social class. Being in the highest quintile for FEV1 was associated with significantly lower likelihood of poor self-reported mental functional health status in males (OR 0.78; 95\% Cl 0.61-0.99), but not in females (OR 1.00; 95\% $\mathrm{Cl} 0.82-1.22$ ).

In conclusion, forced expiratory volume in one second independently predicts self perceived physical well being in a general population across the whole normal distribution of respiratory function.

KEYWORDS: Forced expiratory volume in one second, mental functional health, physical functional health, respiratory function

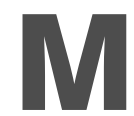
any epidemiological studies have reported an association between respiratory function, measured using forced expiratory volume in one second (FEV1), and mortality [1-4]. Not all these studies have been able to consider adequately whether this relationship was independent of smoking [5], physical activity and prevalent disease [6,7], which are all associated with lung function $[8,9]$.

The short form 36-item questionnaire (SF-36) is a widely used validated generic measure of selfreported health related quality of life (HRQoL) [10]. The relationship between respiratory illness and self-reported functional health [11, 12], and its use in people with respiratory illnesses has been well documented [13-15].

Previous evidence suggests that there is considerable under-diagnosis of obstructive airways disease in the community, which only becomes apparent when FEV1 is used as an objective measure of airways obstruction in a population sample [16]. This has been partly explained by the fact that people may only consult their general practitioners when the quality of their every day life becomes affected [17]. However, the association of FEV1 with selfreported functional health in the general population is less well known. In the present study, the relationship between FEV1 and physical and mental well being was examined, and measured by a generic HRQoL measure (SF-36) in males and females living in the general community.

\section{MATERIALS AND METHODS}

The study population was based on males and females recruited between 1993-1997 as part of the Norfolk (UK) component of the European Prospective Investigation into Cancer (EPIC-Norfolk). Detailed descriptions of the recruitment and study methodology have been previously reported [18]. Males and females aged 40-79 yrs were identified from collaborating general practice registers and were invited by mail to participate. Between 1993 and 1997, 25,639 participants attended a clinic for a baseline assessment. All participants filled in a selfcompleted questionnaire about their lifestyle and health.

\section{AFFILIATIONS}

*Dept of Public Health and Primary Care, University of Cambridge, Strangeways Research Laboratory, \#MRC Dunn Human Nutrition Unit, and

"MRC Epidemiology Unit, Elsie Widdowson Laboratories, Cambridge, UK.

\section{CORRESPONDENCE}

P.K. Myint

Room 311

Strangeways Research Laboratory

Wort's Causeway

Cambridge

CB1 8RN

UK

Fax: 441223740177

E-mail: Pkyawmyint@aol.com

Received:

March 112005

Accepted after revision:

May 092005

\section{SUPPORT STATEMENT}

EPIC-Norfolk is supported by research programme grant funding from Cancer Research UK and the Medical Research Council with additional support from the Stroke Association, British Heart Foundation, Dept of Health, Europe Against Cancer Programme Commission of the European Union, Food Standards Agency and Wellcome Trust. The EPIC-Norfolk HLEQ research programme is supported by a programme grant from the Medical Research Council UK (G0300128). 
At the clinic visits, assessments were made by trained nurses according to standard protocols [19]. Respiratory function was assessed by spirometry [20]. FEV1 was measured twice using a portable spirometer (Micro medical, Rochester, UK), the better of the two measures was used for analyses. Participants' height and weight were measured with participants dressed in light clothing and with their shoes removed. Height was measured to the nearest $0.1 \mathrm{~cm}$ using a stadiometer while weight was measured to the nearest $100 \mathrm{~g}$ using Salter scales. Body mass index (BMI) was calculated as weight in kilograms divided by the square of the height in metres: weight $(\mathrm{kg}) /$ height $\left(\mathrm{m}^{2}\right)$. Cigarette smoking status was derived from responses to the questions "Have you ever smoked as much as one cigarette a day for as long as a year?" and "Do you smoke cigarettes now?" From these smoking status was classified as current smoker, ex-smoker or those who had never smoked.

Occupational social class was classified according to the Registrar General's occupation-based classification scheme in which people with similar levels of occupational skill are allocated into one of five groups [21]. Social class I consists of professionals, social class II includes managerial and technical occupations, social class III is subdivided into nonmanual skilled workers and manual skilled workers, social class IV consists of partly skilled workers, and social class $\mathrm{V}$ comprises unskilled manual workers.

Physical activity was categorised into four physical activity index groups, with level I designated as inactive (most sedentary) and level IV as the most active person. A detailed description of the physical activity index scoring, its validity and its repeatability has been assessed and reported elsewhere [22].

On the health questionnaire, the participants were asked, "Has the doctor ever told you that you have any of the following?" followed by a list of various conditions. For the present study purpose prevalent illness was defined as presence of selfreported major chronic illnesses, including cancer, stroke, myocardial infarction, diabetes mellitus and presence of respiratory illnesses, which include asthma and bronchitis/ emphysema.

The participants were asked to complete a detailed Health and Life Experiences Questionnaire (HLEQ) 18 months later, which included questions on an anglicised version of SF-36 [10] by mail and 20,921 participants responded [23]. The SF-36 comprises of eight subscales, which measure eight dimensions of health including physical functioning, social functioning, role limitations due to physical problems, role limitations due to emotional problems, mental health, energy/vitality, pain and general health perception. The subscales were scored on a scale of health from 0 (worst) to 100 (best). The physical component summary (PCS) and mental component summary (MCS) scores were derived according to algorithms specified by the original developers. PCS and MCS scores were created by aggregating across the eight SF-36 subscales, transformed to $\mathrm{z}$-scores, multiplied by their respective factor score coefficients and standardised as T-scores with mean \pm SD $(50 \pm 10)[24,25]$. The factor score coefficients used were based on a USA population as opposed to a UK population on the basis of uniformity for cross-national comparisons.
For the purpose of the current study, percentiles from the SF-36 scores were used to categorise physical functional health status and mental functional health status. Cut-off points of physical component summary scores of 40 and 55, respectively, were used to approximately identify the bottom and top $20 \%$ of the sample population dividing them into three physical functional health categories: poor $(<40)$, intermediate $(\geqslant 40$ and $<55)$ and good $(\geqslant 55)$. Mental functional health was divided into similar categories using MCS scores of 45 and 60.

The smoking status was re-categorised as current smokers and ex-/nonsmokers, physical activity index as relatively low physical activity (inactive and moderately inactive groups from physical activity questionnaire) and higher physical activity (active and moderately active groups), and occupational social class as manual (occupational social class III manual, IV and V) and nonmanual (social class I, II and III non-manual) social class to give dichotomous variables for some of the analyses.

People were excluded if they had missing values for age, sex, SF-36 scores and FEV1 measured at first health-check. Participants with missing values for particular covariates entered into different models were excluded in individual regression analyses. Ethical approval was obtained from the Norwich Research Ethics Committee (UK).

\section{Statistical analysis}

Statistical analyses were performed separately for males and females. Age at the time of the completion of the SF-36 was included as a covariate in all the models.

The mean summary scores for physical and mental components of SF-36 were tabulated according to the quintiles of FEV1 values. Trend for linearity was tested using ANOVA method.

The relationships between FEV1 and the prevalence and association of poor and good functional health were investigated. Univariate regression models were constructed using SF-36 PCS and SF-36 MCS scores for quintiles of FEV1 and other possible confounding factors, such as height and weight or BMI [26, 27], smoking status [8, 28], physical activity $[29,30]$ and prevalent illnesses [8,31].

Multiple logistic regression analysis was performed to assess the odds ratios for having poor or good physical and mental functional health by individual's FEV1 at baseline after adjusting for age at the time of SF-36 and other confounders mentioned above. Analyses were repeated after excluding those who currently smoke and those who reported any illnesses listed above. Multiple logistic regression analysis was also performed to examine the likelihood of being in good functional health associated with: 1) an increase in FEV1 of $100 \mathrm{~mL} \cdot \mathrm{s}^{-1}$; 2) increase in $5 \mathrm{yrs}$ in age; 3) increase in $5 \mathrm{~cm}$ in height; 4) increase in $5 \mathrm{~kg}$ in weight or one unit of BMI 5) being in nonmanual social class; 6) having higher physical activity; 7) not being a current smoker; and 8) having no major prevalent illnesses.

Analyses were repeated using two subscales (physical functioning and mental health) that contributed mainly to summary scores to examine the consistency of findings using crude scores as well as the derived weighted summary scores 
$[32,33]$. Age-stratified analyses was performed (stratified into three age groups: $<55,55-64$ and $\geqslant 65$ yrs) for multiple logistic regression models examining the impact per increase in FEV1 of $100 \mathrm{~mL} \cdot \mathrm{s}^{-1}$.

\section{RESULTS}

There were 19,535 males and females who had SF-36 summary scores available from the HLEQ. The analyses were based on 16,738 participants $(7,402$ males and 9,336 females $)$, mean $\pm S D$ age $58.5 \pm 9.15$ yrs, who had available data on FEV1 at baseline. There were no material differences between who responded to the HLEQ and those who did not in terms of mean age, height and BMI. There were a higher proportion of nonmanual occupational social classes and a lower proportion of people with prevalent illness in responders compared with nonresponders. Exclusion of people who currently smoke left 14,906 participants (6,578 males and 8,328 females) and exclusion of males and females who reported any cancer, stroke, myocardial infarction, diabetes, asthma and bronchitis / emphysema left 12,737 participants $(5,624$ males and 7,113 females) for the subgroup analyses.

Table 1 shows the distribution of characteristics according to FEV1 category classified by sex-specific quintile ranges for males and females. FEV1 category 1 represents the lowest quintile group, whilst category 5 represents the highest. In this unadjusted table, males and females in the higher FEV1 categories were younger, taller, heavier and had higher mean reported physical functional health measured by SF-36 PCS scores. There was no trend for mental functional health measured by SF-36 MCS scores. There were also higher proportions of people with higher physical activity, nonsmokers, in nonmanual occupational social classes, and without prevalent illnesses in the higher FEV1 categories. The patterns were similar in both males and females apart from smoking status. Repeating the analyses using two main subscales of SF36 showed results consistent with the findings above (data not shown).

Table 2 shows mean scores of SF-PCS and SF-36 MCS scores by FEV1 categories, first age adjusted, then adjusted for age and other covariates which were: weight or BMI, height, physical activity, social class (manual/nonmanual), smoking status and prevalent illness. Physical functional health scores differed significantly between quintile groups of FEV1 in both males and females after age adjustment and differences were only slightly attenuated after adjustment for other covariates. Although, with the large numbers, there were some significant differences in mental functional health measured by SF-36 MCS scores that did not show consistent patterns in comparison with physical scores.

Table 3 shows the likelihood of being in good or poor functional health defined by the lowest and the highest 20th percentile of SF-36 scores in different FEV1 categories in various models. In both males and females, having higher FEV1 in the top fifth compared with the bottom fifth, was associated with approximately a doubling in the likelihood of reporting good physical functional health and halving the likelihood of reporting poor physical health after age adjustment. These were somewhat attenuated, but still highly significant and with consistent trends after adjusting for covariates, or excluding from analyses current smokers, or those with prevalent illnesses (data not shown). In marked contrast, for mental functional health while there also appeared to be lower likelihood of reporting poor mental functional health in those in the four higher FEV1 categories compared with the lowest, there was no consistent or significant trend.

Table 4 shows the multiple logistic regression models, which estimate the likelihood of having good or poor physical and mental functional health for every increase in FEV1 of $100 \mathrm{~mL} \cdot \mathrm{s}^{-1}$ in comparison with increase in age by $5 \mathrm{yrs}$, height by $5 \mathrm{~cm}$, weight in $5 \mathrm{~kg}$ and/or one unit of BMI, being in nonmanual social class, having higher physical activity, being non/ex-smoker compared with current smoker, and being free of known prevalent illnesses. Age-stratified analyses are presented in table 5 (age and other covariates adjusted as model A (weight in $5 \mathrm{~kg}$ ) or model B (BMI)).

In both males and females, higher FEV1 was independently associated with higher odds of reporting good physical functional health, and the magnitude of relationship in terms of an increase in FEV1 of $100 \mathrm{~mL} \cdot \mathrm{min}^{-1}$ was comparable with being in nonmanual occupational social class, having higher physical activity and not being a current smoker. Advancing age appeared to be the factor associated with good mental functional health and a higher FEV1 was not related to good mental functional health.

Repeating the analyses using five levels of occupational social class and three categories of smoking did not alter the findings.

\section{DISCUSSION}

The SF-36 is the most well known of the instruments developed from two large-scale studies carried out in the USA (the Rand Health Insurance Experiment and the Medical Outcomes Study) [34-37]. It has been extensively validated against factors such as work capacity, disease symptoms, use of care services and measures of mental health [38]. The SF-36 has been most commonly used to determine: 1) the patients' point of view or an outcome in relation to an intervention on a particular condition (before and after studies) [39]; or 2) the effect of a condition on HRQoL [40]. The instrument has also been used as a multidimensional measure of healthy ageing [41]. It has been shown to be widely acceptable to the patients or participants studied [42].

The independent relationship between respiratory function measured by FEV1 and good or poor functional health measured by the SF-36 was investigated. Higher FEV1, analysed either as a categorical or continuous variable, was found to be associated with a higher likelihood of self-reported good and lower likelihood of poor physical functional health. In contrast, FEV1 was not consistently related to the likelihood of being in good mental functional health. The association with poor mental functional health appeared to be much more a threshold one, with those in the lowest fifth for FEV1 more likely to report poor mental functional health than those in the other four groups, but without the apparent continuous trend. This association was consistent in repeated analyses using the mental health subscale instead of the MCS score, indicating this was independent of any weighting of the different components. 
TABLE 1 Distribution of characteristics of the EPIC-Norfolk cohort by forced expiratory volume in one second (FEV1) quintile categories

\section{FEV1 category}

\begin{tabular}{|c|c|c|c|c|c|c|}
\hline & \multicolumn{6}{|c|}{ FEV1 category } \\
\hline FEV 1 quintile ranges $\mathrm{mL} \cdot \mathrm{s}^{-1}$ & $<233$ & $233-274$ & $275-310$ & $311-353$ & $\geqslant 354$ & \\
\hline Age yrs & $65.7 \pm 7.8$ & $62.8 \pm 8.2$ & $59.3 \pm 8.2$ & $56.2 \pm 7.9$ & $51.8 \pm 6.4$ & $<0.0001$ \\
\hline Height $\mathrm{cm}$ & $171 \pm 6.5$ & $172 \pm 6.0$ & $174 \pm 6.1$ & $176 \pm 6.0$ & $178 \pm 5.8$ & $<0.0001$ \\
\hline $\mathrm{FEV} 1 \mathrm{~mL} \cdot \mathrm{min}^{-1}$ & $188 \pm 39$ & $255 \pm 12$ & $293 \pm 10$ & $332 \pm 13$ & $393 \pm 31$ & $<0.0001$ \\
\hline SF-36 PCS & $43.3 \pm 11.2$ & $46.9 \pm 10.0$ & $47.9 \pm 9.4$ & $49.4 \pm 8.8$ & $51.76 \pm 7.4$ & $<0.0001$ \\
\hline SF-36 MCS & $53.1 \pm 9.5$ & $53.8 \pm 8.6$ & $53.2 \pm 8.8$ & $52.9 \pm 8.9$ & $51.8 \pm 9.2$ & $<0.0001$ \\
\hline \multicolumn{7}{|l|}{ Physical activity category } \\
\hline Inactive & $572(38.5)$ & $439(29.8)$ & $375(25.3)$ & $330(22.2)$ & $290(19.6)$ & $<0.0001$ (overall) \\
\hline \multicolumn{7}{|l|}{ Smoking status } \\
\hline Current smoker & $231(15.6)$ & $150(10.3)$ & $167(11.3)$ & $138(9.4)$ & $97(6.6)$ & $<0.0001$ (overall) \\
\hline Ex-smoker & $919(62.2)$ & $864(59.1)$ & $791(53.6)$ & $755(51.2)$ & $680(46.3)$ & \\
\hline Never smoked & $327(22.1)$ & $448(30.6)$ & $519(35.1)$ & $582(39.5)$ & $693(47.1)$ & \\
\hline \multicolumn{7}{|l|}{ Occupational social class } \\
\hline Nonmanual & $843(56.8)$ & $889(60.4)$ & $894(60.3)$ & $963(64.8)$ & $1023(69.3)$ & $<0.0001$ (overall) \\
\hline Manual & $642(43.2)$ & $583(39.6)$ & $589(39.7)$ & $522(35.2)$ & $454(30.7)$ & \\
\hline Prevalent illness & $606(40.8)$ & $416(28.3)$ & $298(20.1)$ & $1228(17.3)$ & $201(13.6)$ & $<0.0001$ \\
\hline \multicolumn{7}{|l|}{ Females } \\
\hline FEV1 quintile ranges $\mathrm{mL} \cdot \mathrm{s}^{-1}$ & $<174$ & $174-203$ & $204-229$ & $230-258$ & $\geqslant 259$ & \\
\hline \multicolumn{7}{|l|}{ Physical activity category } \\
\hline Inactive & 745 (39.6) & $578(31.7)$ & $420(22.6)$ & $364(19.1)$ & $295(15.9)$ & $<0.0001$ (overall) \\
\hline Moderately inactive & $600(31.9)$ & $597(32.7)$ & $648(34.8)$ & $641(33.6)$ & $608(32.7)$ & \\
\hline Moderately active & $334(17.8)$ & $408(22.4)$ & $450(24.2)$ & $520(27.3)$ & $506(27.2)$ & \\
\hline Active & $201(10.7)$ & $242(13.3)$ & $344(18.5)$ & $382(20.0)$ & $449(24.2)$ & \\
\hline \multicolumn{7}{|l|}{ Smoking status } \\
\hline Current smoker & $219(11.8)$ & $172(9.5)$ & $193(10.4)$ & $186(9.8)$ & $163(8.8)$ & $<0.0001$ (overall) \\
\hline Ex-smoker & $670(36.1)$ & $571(31.5)$ & $551(29.8)$ & $560(29.5)$ & $571(30.8)$ & \\
\hline Never smoked & $967(52.1)$ & $1067(59.0)$ & $1103(59.7)$ & $1150(60.7)$ & $1118(60.4)$ & \\
\hline \multicolumn{7}{|l|}{ Occupational social class } \\
\hline Nonmanual & $1122(59.6)$ & $1112(60.9)$ & $1206(64.7)$ & $1263(66.2)$ & $1301(70.0)$ & $<0.0001$ (overall) \\
\hline Manual & $759(40.4)$ & $713(39.1)$ & $658(35.3)$ & $644(33.8)$ & $558(30.0)$ & \\
\hline Prevalent illness & $272(14.5)$ & $210(11.5)$ & $161(8.6)$ & $152(8.0)$ & $117(6.3)$ & $<0.0001$ \\
\hline
\end{tabular}

Data are presented as mean \pm SD and $n(\%)$, unless otherwise stated. BMI: body mass index; SF-36 PCS: short form 36 physical component summary score; SF-36 MCS: short form 36 mental component summary score; Nonmanual: social class I, II and III nonmanual; Manual: social class III manual, IV and V; Prevalent illness: self reported respiratory illness (asthma and bronchitis/emphysema), cancer, stroke, myocardial infarction and diabetes mellitus. Quintile cut-off points for FEV1 categories were 233, 275, 311 and $354 \mathrm{~mL} \cdot \mathrm{min}^{-1}$ for males, and 174, 204, 230 and $259 \mathrm{~mL} \cdot \mathrm{min}^{-1}$ for females. $\# \cdot \mathrm{n}=7402 ;{ }^{\bullet}: \mathrm{n}=9336$. 


\begin{tabular}{|c|c|c|c|c|c|c|c|}
\hline \multirow[t]{3}{*}{ TABLE 2} & \multicolumn{7}{|c|}{$\begin{array}{l}\text { Age and other covariates adjusted mean SF-36 physical and mental component summary scores (SF-36 PCS and SF-36 } \\
\text { MCS scores) for different categories of FEV1 by quintiles ranges of the EPIC-Norfolk cohort\# }\end{array}$} \\
\hline & & \multicolumn{6}{|c|}{ FEV1 categories } \\
\hline & & 1 & 2 & 3 & 4 & 5 & p-value \\
\hline \multicolumn{8}{|c|}{ SF-36 PCS scores } \\
\hline Age adjus & & $44.8 \pm 0.3$ & $47.7 \pm 0.2$ & $47.9 \pm 0.2$ & $48.7 \pm 0.2$ & $50.1 \pm 0.3$ & $<0.0001$ \\
\hline Age and & ther covariate adjusted & $45.8 \pm 0.3$ & $48.0 \pm 0.2$ & $47.8 \pm 0.2$ & $48.3 \pm 0.2$ & $49.4 \pm 0.3$ & $<0.0001$ \\
\hline Age and & ther covariate adjusted" & $45.8 \pm 0.3$ & $48.0 \pm 0.2$ & $47.8 \pm 0.2$ & $48.2 \pm 0.2$ & $49.4 \pm 0.3$ & $<0.0001$ \\
\hline \multicolumn{8}{|l|}{ Females } \\
\hline Age adjus & & $44.9 \pm 0.2$ & $46.7 \pm 0.2$ & $47.9 \pm 0.2$ & $48.0 \pm 0.2$ & $48.9 \pm 0.2$ & $<0.0001$ \\
\hline Age and & ther covariate adjusted & $45.7 \pm 0.2$ & $47.0 \pm 0.2$ & $47.9 \pm 0.2$ & $47.7 \pm 0.2$ & $48.3 \pm 0.2$ & $<0.0001$ \\
\hline Age and & ther covariate adjusted & $52.3 \pm 0.3$ & $53.2 \pm 0.2$ & $53.1 \pm 0.2$ & $53.3 \pm 0.2$ & $52.9 \pm 0.3$ & 0.019 \\
\hline Age and & ther covariate adjusted" & $52.3 \pm 0.3$ & $53.2 \pm 0.2$ & $53.1 \pm 0.2$ & $53.3 \pm 0.2$ & $52.9 \pm 0.3$ & 0.019 \\
\hline \multicolumn{8}{|l|}{ Females } \\
\hline Age adjus & & $50.9 \pm 0.2$ & $51.9 \pm 0.2$ & $52.0 \pm 0.2$ & $52.1 \pm 0.2$ & $51.6 \pm 0.2$ & 0.002 \\
\hline Age and & ther covariate adjusted & $51.4 \pm 0.2$ & $52.1 \pm 0.2$ & $52.0 \pm 0.2$ & $51.9 \pm 0.2$ & $51.3 \pm 0.2$ & 0.042 \\
\hline Age and & ther covariate adjusted" & $51.4 \pm 0.2$ & $52.1 \pm 0.2$ & $51.9 \pm 0.2$ & $51.9 \pm 0.2$ & $51.3 \pm 0.2$ & 0.042 \\
\hline
\end{tabular}

Data presented as mean \pm SE unless otherwise stated. Covariates: participants' height (cm), weight (kg), physical activity, social class category (manual and nonmanual), smoking status and self reported physical illnesses including asthma, bronchitis/emphysema, myocardial infarction, stroke, cancer and diabetes mellitus. FEV1: Forced expiratory volume in one second. ${ }^{\#}$ : males $n=7402$, females $n=9336$; ": Adjustment made for body mass index instead of weight. Quintile cut-off points for FEV1 categories were 233, 275, 311 and $354 \mathrm{~mL} \cdot \mathrm{s}^{-1}$ for males, and 174, 204, 230 and $259 \mathrm{~mL} \cdot \mathrm{s}^{-1}$ for females

\section{Nature of associations}

The possible confounding effects of age, height, weight, BMI, smoking, illnesses and social class on the relationship between FEV1 and self-rated health were examined. In particular, it is possible that factors such as smoking and prevalent illness may both affect respiratory function measured by FEV1, as well as self-perceived health. Although residual confounding cannot be excluded from these, or other unknown confounders, adjustment for these major factors, as well as stratified analyses by age and after excluding those who currently smoke and those who reported physical illnesses including respiratory illness, such as asthma and bronchitis/emphysema, showed consistent findings. Additionally, FEV1 was measured 18 months prior to assessing self-reported functional health and, although due to the short follow-up, this was considered a cross-sectional analysis, the prospective relationship between earlier FEV1 and later functional health assessment reduces the likelihood of reverse causality.

It is plausible that the relationship between FEV1 and selfreported functional health reflects both FEV1 and functional health being indicators of respiratory disease, such as undiagnosed chronic obstructive airway disease [43]. However, it is unlikely this is the only explanation as the association between lower FEV1 and poorer self-reported functional health not only remained after adjusting for, or excluding those with, prevalent illnesses including obstructive airway diseases (asthma, bronchitis/emphysema), but was apparent across the whole normal distribution of FEV1 in the population.
The current findings suggest that there may be a direct association between respiratory function and functional health. It is possible that FEV1 indicates the capacity to perform a physical task and may explain why it is a stronger determinant of physical functional health compared with mental functional health. Since FEV1 measures large airways resistance, lower FEV1 (i.e. increase in large airway resistance or reduced elasticity of the airways in normal physiological state) may result in poor physical functional health to a certain and similar extent, which is associated with an equivalent amount of decline in lung function secondary to physical insult such as smoking or respiratory illness, such as asthma/bronchitis. The plausible biological mechanism behind this phenomenon is beyond the scope of the present study and highlights the need for further evaluation.

\section{Limitations}

There were limitations in the current study. As participants who were willing to provide detailed information and participate in a long-term follow-up study were required, there was only a population response rate of $40-45 \%$ for the baseline and follow-up survey. Nevertheless, the characteristics of this population were comparable with national samples, except with slightly lower prevalence of smokers [18]. The study population's observed summary scores for functional health outcome are comparable with two other UK studies, the health survey for England and the Omnibus Survey in Great Britain, but with a slightly lower mean PCS score compared with the Oxford Health Life Survey (OHLS) [42]. However, OHLS 
TABLE 3 Poor or good functional health status defined using SF-36 PCS and SF-36 MCS 20th and 80th percentile scores for corresponding models of the EPIC-Norfolk cohort for four categories of FEV 1 compared with the first quintile group

\section{FEV 1 Category}

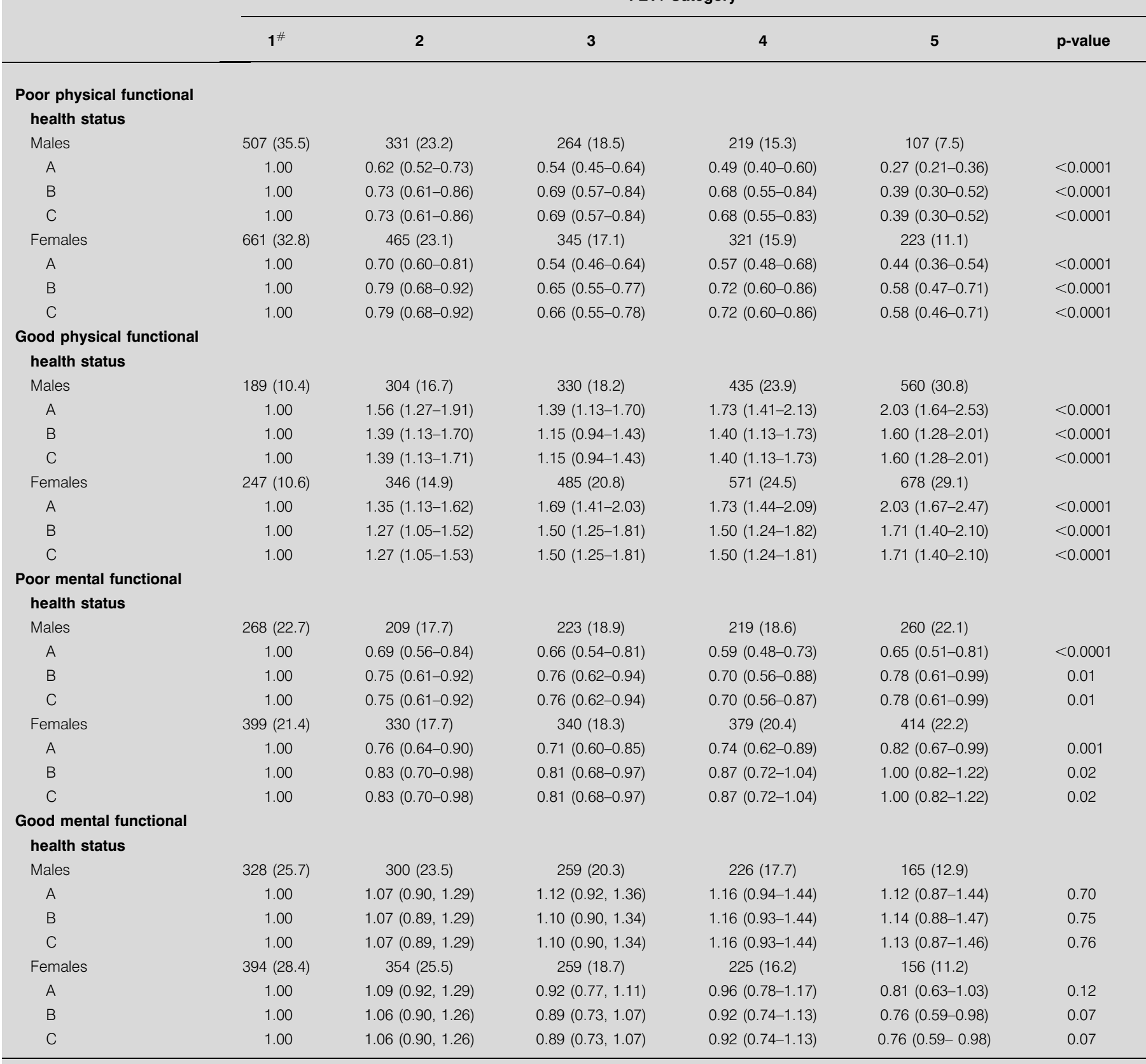

Data presented as odds ratio (95\% confidence interval) or $\mathrm{n}(\%)$, unless otherwise stated. Model A: based on participants' age at the time of SF-36, height, and weight (7,402 males and 9,336 females). Model B: based on participants' age at the time of SF-36, height, weight, smoking status, social class category, physical activity and prevalent illnesses (7,361 males and 9,261 females). Model C: same as model B except body mass index was entered into the model instead of weight. All the variables were included in the same model. SF-36 PCS: Short form 36 physical component summary; SF-36 MCS: short form 36 mental component summary; FEV1: forced expiratory volume in one second. \#: Reference FEV1 category.

comprises a younger cohort and the mean observed scores for the younger (41-65 yrs) EPIC-HLEQ cohort and expected mean scores age-sex standardised to population norms from OHLS were similar [44]. It is likely that the current study population had a narrow range of physical and mental health than would be expected in a general population, as those who were severely compromised physically or mentally would be less likely to participate in the study contributing some selection bias towards healthier people. However, truncation of the distribution, with loss of people in poor functional health or with poor respiratory function, would result only in attenuation of the relationships. This would not explain the 
TABLE 4 Good and poor functional health arbitrarily defined by using SF-36 PCS and SF-36 MCS 80th and 20th percentile scores in males and females of EPIC-Norfolk cohort

\begin{tabular}{|c|c|c|c|c|c|c|c|c|}
\hline & \multicolumn{2}{|c|}{$\begin{array}{l}\text { Good physical functional } \\
\text { health }\end{array}$} & \multicolumn{2}{|c|}{$\begin{array}{l}\text { Good mental functional } \\
\text { health }\end{array}$} & \multicolumn{2}{|c|}{$\begin{array}{l}\text { Poor physical functional } \\
\text { health }\end{array}$} & \multicolumn{2}{|c|}{$\begin{array}{l}\text { Poor mental functional } \\
\text { health }\end{array}$} \\
\hline & Males & Females & Males & Females & Males & Females & Males & Females \\
\hline $\begin{array}{l}\text { FEV } 1100 \mathrm{~mL} \cdot \mathrm{s}^{-1} \\
\text { model A }\end{array}$ & $\begin{array}{c}1.20 \\
(1.09-1.33)^{\mathrm{s}}\end{array}$ & $\begin{array}{c}1.47 \\
(1.29-1.67)^{\text {s }}\end{array}$ & $\begin{array}{c}1.07 \\
(0.95-1.19)\end{array}$ & $\begin{array}{c}0.85 \\
(0.73-0.99)^{*}\end{array}$ & $\begin{array}{c}0.63 \\
(0.56-0.70)^{5}\end{array}$ & $\begin{array}{c}0.64 \\
(0.56-0.74)^{\mathrm{s}}\end{array}$ & $\begin{array}{c}0.86 \\
(0.77-0.96)^{\star *}\end{array}$ & $\begin{array}{c}0.97 \\
(0.85-1.11)\end{array}$ \\
\hline $\begin{array}{l}\text { FEV } 1100 \mathrm{~mL} \cdot \mathrm{s}^{-1} \\
\text { model B }\end{array}$ & $\begin{array}{c}1.20 \\
(1.09-1.33)^{\S}\end{array}$ & $\begin{array}{c}1.47 \\
(1.29-1.67)^{\S}\end{array}$ & $\begin{array}{c}1.07 \\
(0.95-1.19)\end{array}$ & $\begin{array}{c}0.85 \\
(0.73-0.99)^{*}\end{array}$ & $\begin{array}{c}0.63 \\
(0.56-0.70)^{5}\end{array}$ & $\begin{array}{c}0.64 \\
(0.56-0.74)^{5}\end{array}$ & $\begin{array}{c}0.86 \\
(0.77-0.96)^{* *}\end{array}$ & $\begin{array}{c}0.97 \\
(0.85-1.11)\end{array}$ \\
\hline $\begin{array}{l}\text { Age per increase } \\
\text { in } 5 \mathrm{yrs}\end{array}$ & $\begin{array}{c}0.75 \\
(0.72-0.78)^{\mathrm{s}}\end{array}$ & $\begin{array}{c}0.80 \\
(0.77-0.83)^{5}\end{array}$ & $\begin{array}{c}1.38 \\
(1.32-1.44)^{5}\end{array}$ & $\begin{array}{c}1.32 \\
(1.27-1.38)^{\mathrm{s}}\end{array}$ & $\begin{array}{c}1.24 \\
(1.19-1.29)^{5}\end{array}$ & $\begin{array}{c}1.24 \\
(1.20-1.29)^{\mathrm{s}}\end{array}$ & $\begin{array}{c}0.85 \\
(0.82-0.89)^{5}\end{array}$ & $\begin{array}{c}0.89 \\
(0.86-0.92)^{\S}\end{array}$ \\
\hline $\begin{array}{l}\text { Height per increase } \\
\text { in } 5 \mathrm{~cm}\end{array}$ & $\begin{array}{c}1.06 \\
(1.00-1.12)^{\star}\end{array}$ & $\begin{array}{c}1.05 \\
(1.00-1.10)^{*}\end{array}$ & $\begin{array}{c}0.94 \\
(0.89-0.99)^{*}\end{array}$ & $\begin{array}{c}0.98 \\
(0.92-1.03)\end{array}$ & $\begin{array}{c}0.94 \\
(0.89-0.99)^{\star *}\end{array}$ & $\begin{array}{c}0.99 \\
(0.94-1.04)\end{array}$ & $\begin{array}{c}0.99 \\
(0.93-1.05)\end{array}$ & $\begin{array}{c}0.93 \\
(0.89-0.98)^{\star *}\end{array}$ \\
\hline $\begin{array}{l}\text { Weight per increase } \\
\text { in } 5 \mathrm{~kg}\end{array}$ & $\begin{array}{c}0.90 \\
(0.87-0.92)^{\mathrm{s}}\end{array}$ & $\begin{array}{c}0.85 \\
(0.83-0.87)^{5}\end{array}$ & $\begin{array}{c}1.05 \\
(1.02-1.08)^{\star *}\end{array}$ & $\begin{array}{c}1.07 \\
(1.04-1.10)^{\mathrm{s}}\end{array}$ & $\begin{array}{c}1.14 \\
(1.10-1.17)^{\S}\end{array}$ & $\begin{array}{c}1.16 \\
(1.14-1.19)^{\mathrm{s}}\end{array}$ & $\begin{array}{c}1.03 \\
(1.00-1.06)\end{array}$ & $\begin{array}{c}1.03 \\
(1.00-1.05)^{*}\end{array}$ \\
\hline $\begin{array}{l}\text { Non/ex-smoker versus } \\
\text { current smoker }\end{array}$ & $\begin{array}{c}1.15 \\
(0.96-1.39)\end{array}$ & $\begin{array}{c}1.18 \\
(1.00-1.39)^{*}\end{array}$ & $\begin{array}{c}0.90 \\
(0.73-1.11)\end{array}$ & $\begin{array}{c}1.18 \\
(0.95-1.47)\end{array}$ & $\begin{array}{c}0.72 \\
(0.59-0.87)^{\star *}\end{array}$ & $\begin{array}{c}0.76 \\
(0.64-0.90)^{\star \star}\end{array}$ & $\begin{array}{c}0.75 \\
(0.62-0.91)^{\star \star}\end{array}$ & $\begin{array}{c}0.57 \\
(0.49-0.67)^{\S}\end{array}$ \\
\hline $\begin{array}{l}\text { No prevalent } \\
\text { illness versus } \\
\text { prevalent illness }{ }^{\#,+}\end{array}$ & $\begin{array}{c}1.90 \\
(1.63-2.21)^{5}\end{array}$ & $\begin{array}{c}1.64 \\
(1.44-1.87)^{5}\end{array}$ & $\begin{array}{c}1.13 \\
(0.97-1.31)\end{array}$ & $\begin{array}{c}1.18 \\
(1.03-1.36)^{*}\end{array}$ & $\begin{array}{c}0.49 \\
(0.43-0.56)^{5}\end{array}$ & $\begin{array}{c}0.51 \\
(0.46-0.58)^{5}\end{array}$ & $\begin{array}{c}0.71 \\
(0.62-0.83)^{\mathrm{s}}\end{array}$ & $\begin{array}{c}0.75 \\
(0.66-0.84)^{\S}\end{array}$ \\
\hline
\end{tabular}

Data presented as odds ratio (95\% confidence interval). SF-36 PCS: short form 36 physical component summary; SF-36 MCS: short form 36 mental component summary; FEV1: forced expiratory volume in one second. \#: Reference category; ": physical activity index level I and II: physically inactive, level III and IV: physically active; ${ }^{+}$: self reported respiratory illnesses namely asthma and bronchitis/emphysema and other major long standing or life threatening illnesses such as myocardial infarction, stroke, cancer and diabetes mellitus. *: $p<0.05 ;{ }^{* \star}: p<0.01 ;{ }^{s}: p<0.0001$.

TABLE 5 Good and poor functional health arbitrarily defined by using SF-36 PCS and SF-36 MCS 80th and 20th percentile scores of the EPIC-Norfolk cohort for the three age groups\#

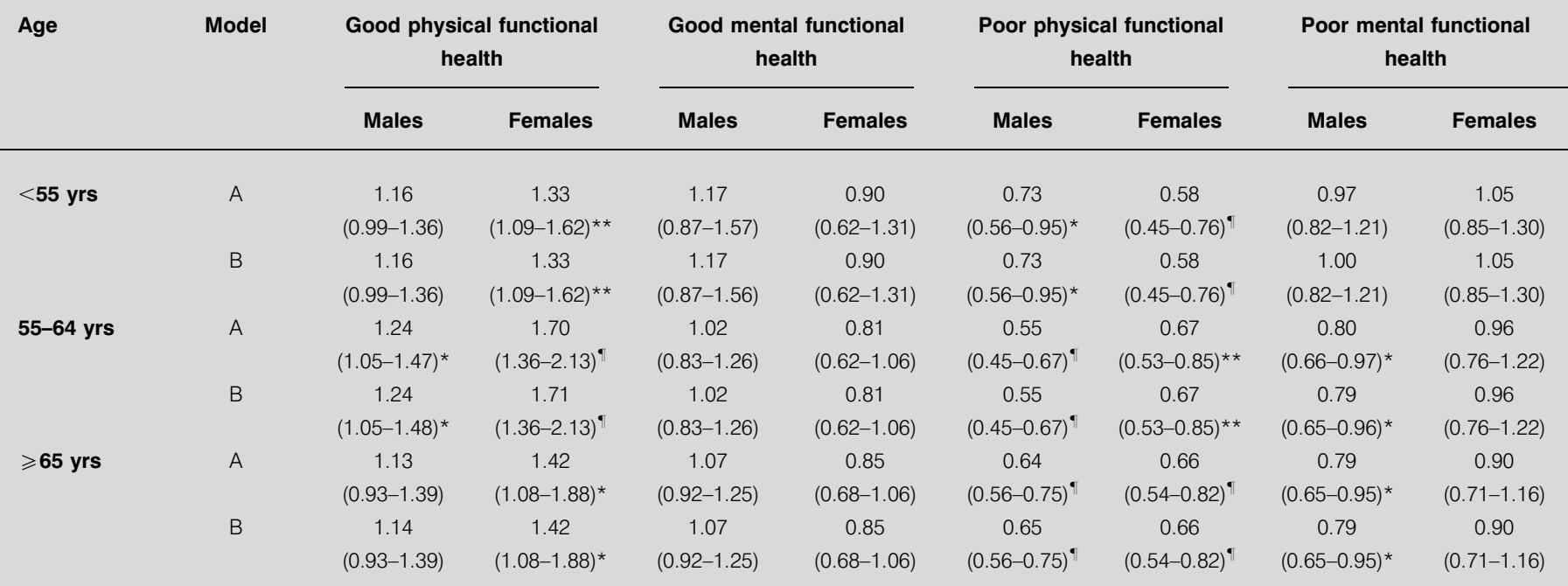

Data presented as odds ratio (95\% confidence interval). SF-36 PCS: short form 36 physical component summary; SF-36 MCS:PI: short form 36 mental component summary. ${ }^{\#}$ : Every increase in $100 \mathrm{~mL} \cdot \mathrm{s}^{-1}$ in forced expiratory volume controlling for age (age at the time of SF-36), every increase in $5 \mathrm{~cm}$ in height, $5 \mathrm{~kg}$ in weight (model A) and 1 unit of body mass index (model B), social class (manual/nonmanual), physical activity (physically inactive/active), smoking (current/ex- or nonsmoker), prevalent illness (yes/no). *: $p<0.05 ;{ }^{* *}: p<0.01 ;{ }^{\uparrow}: p<0.0001$. 
significant associations within the cohort found in this study. Another limitation of using functional health outcome derived from the SF-36 is due to its subjectivity. Nevertheless, subjective health outcomes are relevant to the individual and have been shown to relate to mortality [25].

\section{Implications}

Although the difference in the mean functional component summary scores by FEV1 categories in the present sample was not large in absolute terms, the magnitude was approximately half of the standard deviation of the population mean. To explore how these mean differences translate in practical terms categories were defined with poor and good functional health status using arbitrary percentile cut-off points. Relatively small differences in mean SF-36 PCS and MCS scores were associated with substantial differences in the prevalence and likelihood of being in poor or good physical functional health (table 3). The association was independent of potential confounders and was also consistent after exclusion of people who currently smoke or people with self-reported illnesses.

The magnitude of reduction in mean PCS scores of SF-36 being in the bottom fifth compared with the top fifth for FEV1 was comparable with the reduction in functional health scores associated with a chronic medical condition, such as diabetes, cancer, stroke and myocardial infarction or prevalent mood disorder [23]. Moreover, the present findings also indicate that the estimated magnitude of effect on self-reported physical functional health of being in the bottom fifth compared with the top fifth for FEV1 was greater than that of manual versus nonmanual social class estimated in the regression analyses.

Respiratory function declines with age. The impact of healthrelated behaviours, which are potentially modifiable, such as smoking [5], physical activity [6] and obesity [45] on respiratory function has been well documented. Nutritional factors, such as fruit and vegetable intake, have been suggested to be protective for respiratory function [46, 47]. While these factors may have effects on health independent of respiratory function, they raise the intriguing possibility that it may be possible to attenuate the decline of respiratory function with age. As can be seen from the analyses, even a relatively modest increase in respiratory function is associated with a measurable impact on the prevalence and likelihood of being in either poor or good physical functional health. Identifying whether it is possible to attenuate the decline of respiratory function with age through modest changes in behaviours, such as physical activity, and diet, may have potential in improving health.

In conclusion, maintaining good health in an ageing population is a major challenge in society. The present results highlight the importance of respiratory function for functional health even within the normal population distribution. Understanding the nature of this association may help us understand how to improve health in the ageing population.

\section{ACKNOWLEDGEMENTS}

The authors would like to thank all participants and general practitioners who took part in the study. The authors would also like to thank the staff of EPIC-Norfolk and the institutions that provided funding.
K-T. Khaw, N.E. Day, S.A. Bingham and N.J. Wareham are principal investigators in EPIC-Norfolk population study. P.G. Surtees is the principal investigator of EPIC-Norfolk HLEQ programme. R.N. Luben was responsible for data management, computing and data linkages. P.K. Myint conducted the analysis and wrote the paper along with K-T. Khaw. All coauthors contributed in the writing of this paper. K-T. Khaw is the guarantor.

\section{REFERENCES}

1 Ebi-Kryston KL. Respiratory symptoms and pulmonary function as predictors of 10-year mortality from respiratory disease, cardiovascular disease and all cause in the Whitehall Study. J Clin Epidemiol 1988; 41: 251-260.

2 Strachan DP. Ventilatory function, height, and mortality among lifelong non-smokers. J Epidemiol Community Health 1992; 46: 66-70.

3 Schunemann HJ, Dorn J, Grant BJ, et al. Pulmonary function is a long-term predictor of mortality in the general population: 29-year follow-up of the Buffalo health study. Chest 2000; 118: 656-664.

4 Hole DJ, Watt GCM, Davey-Smith G, et al. Impaired lung function and mortality risk in men and women: findings from the Renfrew and Paisley prospective population study. BMJ 1996; 313: 711-715.

5 Ryan G, Knuiman MW, Ddivitini ML, et al. Decline in lung function and mortality: the Busselton health study. $J$ Epidemiol Community Health 1999; 53: 230-234.

6 Agnarsson U, Thorgeirsson G, Sigvaldason H, et al. Effects of leisure-time physical activity and ventilatory function on risk for stroke in men: the Reykjavik Study. Ann Intern Med 1999; 130: 987-990.

7 Wannamethee SG, Shaper AG, Ebrahim S. Respiratory function and risk of stroke. Stroke 1995; 26: 2004-2010.

8 Burchfiel CM, Enright PL, Sharp DS, et al. Factors associated with variations in pulmonary function among elderly Japanese-American men. Chest 1997; 112: 87-97.

9 Twisk JW, Staal BJ, Brinkman MN, et al. Tracking of lung function parameters and the longitudinal relationship with lifestyle. Eur Respir J 1998; 12: 627-634.

10 Brazier JE, Harper R, Jones NMB, et al. Validating the SF-36 health survey questionnaire - new outcome measure for primary care. BMJ 1992; 305: 160-164.

11 Spencer S, Calverley PMA, Burge PS, Jones PW. Health status deterioration in patients with chornic obsrtructive pulmonary disease. Am J Respir Crit Care Med 2001; 163: 122-128.

12 Chang JA, Curtis JR, Patrick DL, Raghu G. Assessment of health-related quality of life in patients with interstitial lung disease. Chest 1999; 116: 1175-1182.

13 Ware JE, Kemp JP, Buchner DA, et al. The responsiveness of disease-specific and generic health measures to changes in the severity of asthma among adults. Qual Life Res 1998; 7: 235-244.

14 Martinez TY, Pereira CA, dos Santos ML, et al. Evaluation of the short-form 36-item questionnaire to measure healthrelated quality of life in patients with idiopathic pulmonary fibrosis. Chest 2000; 117: 1627-1632.

15 Mahler DA, Mackowiak JI. Evaluation of the shortform 36-item questionnaire to measure health-related 
quality of life in patients with COPD. Chest 1995; 107: 1585-1589.

16 Van den Boom G, van Schayck CP, Rutten-van Molken MP, et al. Active detection of chronic obstructive pulmonary disease and asthma in the general population, results and economic consequences of the DIMCA program. Am J Resp Crit Care Med 1998; 158: 1730-1738.

17 Van den Boom G, Rutten-van Molken MPMH, Tirimanna PRS, et al. Association between health-related quality of life and consultation for respirtory symptoms: results from the DIMCA programme. Eur Respir J 1998; 11: 67-72.

18 Day N, Oakes S, Luben R, Khaw KT, Bingham S, Welch A. EPIC-Norfolk: Study design and characteristics of the cohort. Br J Cancer 1999; 80: Suppl. 1, 95-103.

19 Lohman T, Roche A, Martorell R. Anthropometric standardization reference manual. Champaign, IL, USA, Human Kinetics Books, 1991.

20 Cox B, Huppert F, Whichelow M. The Health and Lifestyle Survey: seven years on. Aldershot, UK, Dartmouth Publishing Company, 1993.

21 Elias P, Halstead K, Prandy K. CASOC: Computer-Assisted Standard Occupational Coding. London, HMSO, 1993.

22 Wareham NJ, Jakes RW, Rennie KL, et al. Validity and repeatability of a simple index derived from the short physical activity questionnaire used in the European Prospective Investigation into Cancer and Nutrition (EPIC) study. Public Health Nutrition 2003; 6: 407-413.

23 Surtees PG, Wainwright NJW, Khaw KT, Day NE. Functional health status, chronic medical conditions and disorders of mood. Br J Psychiatry 2003; 183: 299-303.

24 Ware JE, Snow KK, Kosinski M, Gandek B. SF-36 Health Survey: manual and interpretation guide. Boston, MA, USA Nimrod Press; 1993.

25 Ware JE, Kosinski M, Keller S. SF-36 physical and mental health summary scales: a user's manual, Boston, MA, USA. The Health Institute, New England Medical Center, Boston; 1994.

26 Harik-Khan RI, Fleg JL, Muller DC, Wise RA. The effect of anthropometric and socioeconomic factors on the racial difference in lung function. Am J Respir Crit Care Med 2001; 164: 1647-1654.

27 Carey IM, Cook DG, Strachan DP. The effects of adiposity and weight change on forced expiratory volume decline in a longitudinal study of adults. Int J Obes Relat Metab Disord 1999; 23: 979-985.

28 Anthonisen NR, Connett JE, Murray RP. Smoking and lung function of Lung Health Study participants after 11 years. Am J Respir Crit Care Med 2002; 166: 675-679.

29 Jakes RW, Day NE, Patel B, et al. Physical inactivity is associated with lower forced expiratory volume in 1 second. European Prospective Investigation into Cancer Norfolk prospective population study. Am J Epidemiol 2002; 156: 139-147.

30 Cheng YJ, Macera CA, Addy CL, et al. Effects of physical activity on exercise tests and respiratory function. $\mathrm{Br} J$ Sports Med 2003; 37: 521-528.

31 Enright PL, Kronmal RA, Higgins MW, et al. Prevalence and correlates of respiratory symptoms and disease in the elderly: Cardiovascular Health Study. Chest 1994; 106: 827-834.

32 Taft C, Karlsson J, Sullivan M. Do SF-36 summary component scores accurately summarize subscale scores? Qual Life Res 2001; 10: 395-404.

33 Ware JE, Kosinski M. Interpreting SF-36 summary health measures: a response. Qual Life Res 2001; 10: 405-413, discussion 415-420.

34 Book RH, Ware JE, Roger WR, et al. Does free care improve adults' health? Results from a randomised controlled trial. New Engl J Med 1983; 309: 1426-1434.

35 Ware JE, Brook RH, Rogers WH, et al. Comparison of health outcomes at a health maintenance organisation with those of fee-for-service care. Lancet 1986; 1: 1017-1022.

36 Tarlov AR, Ware JE, Greenfield S, Nelson EC, Perrin E, Zubkoff M. The Medical Outcomes Study: an application of methods for monitoring the results of medical care. J Am Med Assoc 1989; 262: 925-930.

37 Ware JE, Sherbourne C. The MOC 36 item short-form health survey 1: conceptual framework and item selection. Med Care 1992; 30: 473-483.

38 Mc Dowell I, Newell C. Measuring health. A guide to rating scale and questionnaires, 2nd Edn. New York, Oxford University Press, 1996.

39 Yusen RD, Lefrak SS, Gierada DS, et al. A prospective evaluation of lung volume reduction surgery in 200 consecutive patients. Chest 2003; 123: 1026-1037.

40 Sciolla A, Patterson TL, Wetherell JL, McAdams LA, Jeste DV. Functioning and well-being of middle-aged and older patients with schizophrenia: measurement with the 36-item short-form (SF-36) health survey. Am J Geriatr Psychiatry 2003; 11: 629-637.

41 Michael YL, Colditz GA, Coakley E, Kawachi I. Health behaviours, social networks, and healthy ageing: crosssectional evidence from the Nurses' Health Study. Qual Life Res 1999; 8: 711-722.

42 Jenkinson C, Wright L, Coulter A. SF-36, Quality of life measurements in health care; a review of measures and population norms of the UK SF-36. Oxford, Health Service Research Unit, 1993.

43 Lundbäck B, Gulsvik A, Albers M, et al. Epidemiological aspects of early detection of chronic obstructive airway diseases in the elderly. Eur Respir J 2003; 21: Suppl. 40, 3s-9s.

44 Surtees PG, Wainwright NWJ, Khaw K-T. Obesity, confident support and functional health: cross-sectional evidence from the EPIC-Norfolk cohort. Int J Obes Relat Metab Disord 2004; 28: 748-758.

45 Canoy D, Luben R, Welsh A, et al. Abdominal obesity and respiratory function in men and women in the EPICNorfolk study, United Kingdom. Am J Epidemiol 2004; 159: 1140-1149.

46 McKeever TM, Scrivener S, Broadfield E, Jones Z, Britton J, Lewis SA. Prospective study of diet and decline in lung function in a general population. Am J Respir Crit Care Med 2002; 165: 1299-1303.

47 Kelly Y, Sacker A, Marmot M. Nutrition and respiratory health in adults: findings from the Health Survey for Scotland. Eur Respir J 2003; 21: 664-671. 